\title{
CHRONICLE
}

\section{The Mission of the African University: The Legon Statement ${ }^{\star}$}

\section{STATEMENT OF PURPOSE}

The present seminar seeks to identify proposals for concrete interuniversity cooperation in the field of university governance and management. As a result, these institutions will be better equipped to engage in constructive dialogue with national decision makers in higher education.

The Seminar continues the analysis of higher education trends and issues in the field of university management, as dealt with in other recent fora, notably:

- The Unesco Reflection on the Role of Higher Education in Society (Dakar, 1991);

- MINEDAF VI (Dakar, 1991);

- Unesco/AAU Seminars on Higher Education Management (Dakar, 1990; Harare, 1991).

It is generally agreed that more efficient university governance and management are the keys to the improvement of higher education in Africa. The seminar series, by bringing together a specific target audience of African Vice-Chancellors, Rectors and top-level administrators, aims at forging a consensus of views on three main areas: - the future mission of the African University (Accra, 1991);

- its management (Dakar 1992);

- its efficient use of resources (Cairo 1992).

Each meeting will yield a statement which will be incorporated into a Plan of Action, specifically for strengthened management at African universities. This will complement existing initiatives including:

- the Action Plan 1992-2002, drawn up by the Consultation of Experts on 'Trends and Issues in Higher Education in Africa' (Dakar, 1991);

- the Special Programme for the Improvement of Higher Education in Africa, elaborated by a meeting of experts in Dakar in 1988 and endorsed at MINEDAF VI (1991).

This Plan of Action will then be submitted to a special committee of African university leaders who will be responsible for defining its operational aspects.

Finally, the operationalized Plan of Action will be submitted to donors for funding before the end of 1992. For Unesco, the proposals presented will be considered within the framework of Project UNITWIN, to be launched in 1992 to help strengthen interuniversity cooperation in key areas related to sustainable development. Effective university management is regarded as one such domain, since higher education and the development process are inextricably linked.

At this point, it is useful to reconfirm the missions of the African university as stated at MINEDAF V and which promote the following concepts:

- the training of high-level specialists in all areas necessary for national development;

- the endogenous development of science and technology;

- the safeguard of cultural identity and the promotion of culture; - the improved functioning of the education system as a whole. The following are the main areas for concrete action related to the future mission of the African university as identified by the Accra Seminar.

\section{Proposals for further consideration and action}

1. The development of strategies to permit the participation of universities in national policy making in the field of higher education and in that of development generally; Unesco, AAU and other interested agencies can assist in this task.

2. There should be immediate efforts to implement concrete proposals already in existence which are designed to strengthen higher education. These include the project to mark the 25 th anniversary of the AAU, which provides for staff development and exchanges inter-university cooperation in the field of university publications and further research on degree recognition.

3. Inter-university cooperation should be a tenet of enhanced managerial efficiency; to this end, Chairs in higher education management/staff development could be set up to link universities within the framework of the Unesco UNITWIN Project and with support from interested donors.

4. Universities, through their charters and mission statements, should recognize the importance of key principles such as institutional autonomy, academic freedom and equal study and employment opportunities for men and women.

5. The rapid establishment of institutional mechanisms, including performance indicators to permit regular self-evaluation and orientation by universities.

6. African universities must rapidly construct effective strategies to rationalize their meagre resources and to obtain a sound return on those available; they could explore ways and means to diversify their funding sources, notably by setting up units to develop their contacts with industry and the economic sector and to expand their consultancy services to the comnunity.

7. The establishment of sub-regional centres of excellence in specific disciplines to ensure the enhanced quality and relevance of university teaching, training and research.

8. Wide participation by vice-chancellors and rectors in university leadership programmes. This is vital in view of the trend towards limited mandates. These programmes should be complemented by training workshops in priority areas of university management such as financing, computerization and library facilities for specialized staff concerned.

9. Commitment to optimize the uses of information technology in university management should be based on rigorous needs analyses, feasibility studies, detailed costing and maintenance requirements and closely monitored pilot projects in order to obtain the best results.

10. The potential offered by open learning systems merits immediate attention in order to increase its uses in African universities; this would include stringent analysis of the costs involved.

11. As an underlying principle of enhanced managerial efficiency, the cultural context of African universities must be taken into consideration in both national and institutional policy making.

\footnotetext{
These are the official conclusions of the Unesco/AAU (Association of African Universities) Seminar on 'Higher Education Governance and Management of African Universities', Accra, Ghana, 25-29 November, 1991.
} 